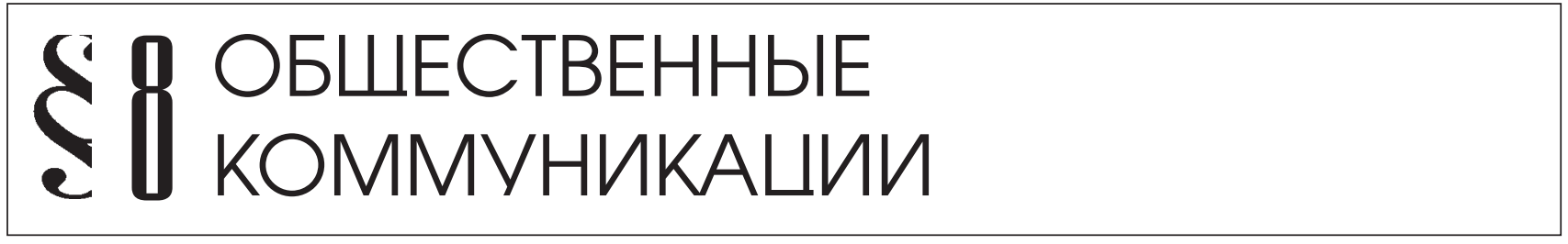

Тимохин К.М., Кабылинский Б.В.

\title{
ФАБРИКИ МЫСЛИ КАК ПЕРСПЕКТИВНОЕ НАПРАВЛЕНИЕ РАЗВИТИЯ ГРАЖДАНСКОГО ОБЩЕСТВА В РОССИИ (НА ПРИМЕРЕ АССОЦИАЦИИ ИМПОРТЕРОВ И ДИСТРИБЬЮТОРОВ СТРОИТЕЛЬНОЙ И ОТДЕЛОЧНОЙ КЕРАМИКИ)
}

\begin{abstract}
Аннотация: Российские некоммерческие организаџии, в частности, ассоциации дистрибьюторов и импортеров имеют определенный потенциал в сфере оптимизации принятия государственных решений. В статье рассматриваются перспективы развития гражданского общества в России на примере функиионирования фабрик мыслл. Посредническая функиия, экспертная оценка, а также налаживание проиессов коммуникации между мальм и средним бизнесом, выполняемые некоммерческими организачиями - ключевые характеристики фабрик мысли. При этом очевидна необходимость соответствия формируюшихся институтов российскому национальному и культурно-историческому опыту. Фактически функиионирование фабрик мысли в России - это форма лоббистской деятельности, которая в перспективе может быть институционализирована. Авторы статьи ставят перед собой цель внести вклад в преодоление существуюших скептических оценок динамики развития гражданского общества. На конкретном примере деятельности Ассоииачии дистрибьюторов и импортеров строительной и отделочной керамики доказывается, что некоммерческие организации в России имеют определенный потенциал в сфере принятия государственных решений и повышения эффективности демократического транзита в целом.

Review: The Russian non-commercial organizations, and associations of distributors and importers in particular have some potential in the sphere of optimization of the state decision-making. The article evaluates the perspectives for the development of civil society in Russia taking think tanks as an example. The intermediary functions, expert evaluation and facilitation of communication processes among small-scale and medium-scale businesses, which are performed by non-commercial organizations, are key characteristic features of think tanks. At the same time it is obvious that the forming institutions should correspond with the Russian national, cultural and historical experiences. In fact, functioning of the think tanks in Russia is a form of lobbying activity, which may be institutionalized in the future. The authors have a goal to make an impact on the overcoming of the existing skeptical evaluations of the dynamics of development of the civil society. Taking a specific example of the Association of Distributors and Importers of Construction and Decoration Ceramics, the authors prove that non-commercial organizations in Russia have certain potential in the sphere of state decision-making and making the democratic transit as a whole more efficient.
\end{abstract}

Ключевые слова: гражданское общество, лоббизм, фабрика мысли, некоммерческие организаиии, малый, средний бизнес, принятие государственных решений, коммуникачия, экспертная оченка, посредничество, разрешение конфликтов Keywords: civil society, lobbying, think tank, non-commercial organizations, small-scale business, medium-scale business, state decision-making, communication, expert evaluation, intermediary, conflict settlement.

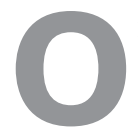
ценка современного состояния российского общества, происходящих внутри него социально-политических процессов со всей очевидностью указывает на то, что расслоение общества по уровню дохода превращается в одну из наиболее острых проблем. Доминирующими факторами, под влиянием которых происходило формирование социальной структуры общества в России, явились итоги приватизации в 90-е годы XX века, повышение роли плутократии и неравномерное распределение капитала в пользу узкого круга финансовых и промышленных групп. В результате, российское общество приобрело 
опасный признак сверхполярной дифференциации по уровню дохода.

Отражением этого признака является чрезвычайно незначительная роль в экономике и социальной жизни страны малого и среднего бизнеса, что разительно отличает современную Россию от других стран. При этом, согласно официальным статистическим сведениям, значительная масса трудоспособного населения страны занята именно в предприятиях и фирмах, относящихся к этой категории ${ }^{1}$. В связи с этим представителей малого и среднего бизнеса следует расценивать в качестве важной составляющей российского гражданского общества.

В последнее время всё чаще затрагивается тема необходимости развития малого и среднего бизнеса, существующих проблем, тормозящих этот процесс. В процессе поиска путей преодоления таких проблем обнаруживается взаимосвязь состояния малого и среднего бизнеса и степени реальной возможности гражданского общества оказывать влияние на ход социально значимых преобразований.

Формой консолидации усилий предприятий малого и среднего бизнеса в направлении защиты своих интересов и одновременно инструментом выработки подходов в решении общих проблем стала получившая распространение практика создания некоммерческих организаций в виде ассоциаций, создаваемых по отраслевому признаку или общности сферы потребления поставляемой на внутренний рынок продукции.

Широко известны подобные ассоциации, созданные предприятиями тяжёлой промышленности, топливноэнергетического комплекса и транспорта. Они уже эффективно функционируют и располагают необходимыми ресурсами, в том числе и для обеспечения своего участия в политическом процессе. Некоммерческие организации малого и среднего бизнеса по большей части находятся в стадии становления. При этом приходится констатировать, что деятельность таких некоммерческих организаций по обеспечению законных интересов малого и среднего бизнеса в современной России существенно затруднена.

В современной России, по нашему мнению, эффективное функционирование институтов гражданского общества, в той или иной степени ориентированных на повышение роли малого и среднего бизнеса в экономической жизни страны, возможно лишь в случае, когда организация способна осуществлять эффективное лоббирование собственных и партнерских интересов, обеспечивать надёжную защиту законных прав её членов. Здесь необходимо отметить, что значение понятия«лоббизм» не сводится к сугубо отрицательному, вредному для развития современ-

\footnotetext{
${ }^{1}$ Калинин A.B. Малый и средний бизнес России: численность и отраслевое распределение. // Российское предпринимательство. № 4. 2011. - C. 46-51.
}

ного российского государства, смыслу. В современном российском политическом дискурсе как на теоретическом, так и практическом уровне все больше внимания уделяется разработке понятия «цивилизованный лоббизм»и и его роли в процессе становления и развития институтов гражданского общества в России.

Специфика формирования институтов гражданского общества в каждой стране во многом зависит от её культурно-исторического опыта ${ }^{2}$. В связи с этим, в российских условиях, по нашему мнению, нецелесообразно развивать альтернативные, по отношению к устоявшимся формам, типы интеракций между государством, бизнесом и гражданским обществом. Более адекватной формой представляется использование потенциала легитимного лоббизма в конструктивном ключе. Лоббизм в данном случае означает защиту законных интересов бизнес-структур. Таким образом, повышение активности некоммерческих организаций, занимающихся легитимным лоббированием интересов малого и среднего бизнеса, следует признать в российских политических условиях перспективным направлением развития гражданского общества.

Несмотря на возможный скепсис в отношении характера и уровня развития гражданского общества в России, ввиду наличия таких проблем, как «низкая общественная активность граждан в масштабах всей страны (не только в регионах, но и в Москве и Санкт-Петербурге), недостаточная наглядность позитивной роли общественных структур, слабая информированность о них и серьезный дефицит доверия граждан к структурам власти и институтам гражданского общества» ${ }^{3}$, некоторые некоммерческие организации, которые в данном случае вполне уместно было бы обозначить как «фабрики мысли», функционируют достаточно эффективно.

Понятие «фабрика мысли» введено в отечественный политологический дискурс А.Ю. Сунгуровым и означает институт гражданского общества, выполняющий образовательную, креативную, коммуникационную функцию ${ }^{4}$ и отличающийся автономией, самостоятельностью в осуществлении посредничества между экспертно-аналитическим сообществом и властью в процессе принятия государственных решений. Политическая активность таких фабрик мысли, как Центр политических техно-

\footnotetext{
${ }^{2}$ Манойло А.В. Роль культурно-цивилизационных моделей и технологий информационно-психологического воздействия в разрешении международных конфликтов. Текст диссертации на соиск. уч. ст. доктора политических наук. - М., 2009. - С. 9.

${ }^{3}$ Волков Д.А. Перспективы гражданского общества в России. Доклад Аналитического Центра Юрия Левады (Левада-Центр). - М., 2011. - C. 50.

${ }^{4}$ Сунгуров А.Ю. Институты-медиаторы и их развитие в современной России. Фабрики мысли и центры публичной политики. //Полис.2012. № 4.- С. 105.
} 
DOI: $10.7256 / 1811-9018.2013 .8 .9015$

При цитировании этой статьи сноска на dоі обязательна

\section{Право и политика $8(164) \cdot 2013$}

логий, Московская школа политических исследований, Совет по внешней и оборонной политике проявляется в следующих формах: сопровождение избирательного процесса; экспертное обеспечение деятельности государственных структур и их лидеров; содействие консолидации политического режима в современной России за счет выполнения функции переговорных площадок, «на которых озвучиваются реальные проблемы современного общества, разрабатываются проекты их решения, проекты нормативных актов и т.д.»5. Фабрики мысли фактически выполняют функции института-медиатора, снимающего нагрузку с судебных органов РФ, при этом выполняя сервисную функцию по налаживанию диалога между властью и гражданским обществом. В соответствии с нашей гипотезой, эффективное функционирование российских фабрик мысли, ориентированных в числе прочего на решение задач в сфере экономики, также зависит от способности осуществлять легитимную лоббистскую деятельность. В основу такой гипотезы положена оценка функционирования одной из ассоциаций в сфере малого и среднего бизнеса.

В 2008 году в Москве состоялось первое Общее собрание членов Ассоциации импортеров и дистрибьюторов строительной и отделочной керамики (далее Ассоциация. - Прим. авторов) и по итогам собрания был принят Устав, что закрепило учреждение этой организации. В соответствии с Уставом, «главной целью создания Ассоциации является координация предпринимательской деятельности членов Ассоциации, способствующей развитию и формированию рынка строительной и отделочной керамики, повышения качеств предоставляемых услуг, а также защита имущественных интересов членов Ассоциации в государственных органах, органах местного самоуправления, иных негосударственных структурах и организациях» ${ }^{6}$. Для реализации данной цели Ассоциация занимается такими видами деятельности, как «содействие в осуществлении издательской деятельности в установленном законодательством порядке; содействие в обеспечении равных условий деятельности участников рынка строительной и отделочной керамики; содействие в упрочнении деловой репутации членов Ассоциации для продвижения их товаров и услуг на внутреннем и внешнем рынках; содействие в защите экономических, юридических и иных интересов членов Ассоциации в органах государственной власти и местного самоуправ-

\footnotetext{
${ }^{5}$ Сунгуров А.Ю. Институты-медиаторы и их развитие в современной России. Современные палаты и консультативные советы федеральный и региональный опыт. // Полис. 2012. № 1. - С. 169.

6 Устав Ассоциации дистрибьюторов и импортеров строительной и отделочной керамики.[электронный ресурс] // Официальный сайт Ассоциации. URL: http://www.askeramika.ru/index. php?page=docustav. (дата обращения 20.05.2013).
}

ления; содействие в налаживании и развитии деловых контактов с заинтересованными зарубежными фирмами, российскими предприятиями и организациями; оказание информационно-консультационных услуг; проведение социологических и маркетинговых исследований; разработка отраслевых стандартов продукции, документов и квалификационных требований и т.д.»7. Устав Ассоциации закрепляет в числе значимых такие роды деятельности, как лоббизм, медиация и налаживание коммуникационных процессов с российскими государственными институтами и международными организациями. Таким образом, исходя из цели и видов деятельности Ассоциации, представляется возможным определить данный институт как соответствующий сути понятия «фабрика мысли». Анализ деятельности Ассоциации, по существу- реализации заявленной в Уставе программы, позволяет сделать вывод о способности этой фабрики мысли решать практические задачи, в первую очередь в сфере легитимного лоббирования интересов малого и среднего бизнеса.

За период своего существования Ассоциация приняла активное участие в налаживании диалога между предприятиями, входящими в её состав, и органами исполнительной и законодательной власти. В частности, от имени Ассоциации неоднократно направлялись обращения, содержащие конструктивные предложения, касающиеся функционирования предприятий малого и среднего бизнеca, в государственные структуры различной компетенции, включая аппарат Президента России.

Особую ценность имеет опыт работы Ассоциации в сфере законотворчества. Аккумулировав мнения членов и изучив существующую ситуацию в сфере торговой деятельности, Ассоциация выступила с конкретными предложениями по улучшению Федерального закона от 28 декабря 2012 года № 381-Ф3 «Об основах государственного регулирования торговой деятельности в Российской Федерации» (далее - Ф3 № 381. -Прим авторов). Уместно отметить, что в целом данный нормативный акт имеет весьма позитивное значение для упорядочивания отношений между поставщиками товаров и торговыми предприятиями, так как ограничивает срок возврата денег за поставленный товар, ограничивает размер бонусов, повышает транспарентность в данной сфере за счёт размещения информации об условиях отбора поставщиков продовольственных товаров в сети Интернет. Однако его нормы трудно применить к непродовольственным товарам, в том числе - строительной и отделочной керамики, поэтому Ассоциация инициировала внесение в ФЗ № 381 внесение соответствующих поправок.

С учётом актуальных задач, стоящих перед членами Ассоциации, другим значимым направлением работы в

\footnotetext{
${ }^{7}$ Там же.
} 
сфере налаживания диалога с федеральными органами исполнительной власти, стала работа по организации взаимодействия с рядом структурных подразделений ФТС России. Примером такого взаимодействия может служить выработка взаимоприемлемых подходов к проблеме контроля соблюдения соответствия требованиям безопасности ввозимых на территорию России товаров в целях обеспечения полноты проверочных действий и исключения неоправданных затрат, влекущих удорожание импортируемых товаров. В результате совместной работы адекватные механизмы контроля были выработаны.

Ввиду того обстоятельства, что Ассоциация объединяет предприятия, осуществляющие внешнеэкономическую деятельность, она должна быть готова решать задачи, выходящие за пределы юрисдикции Российской Федерации, что стало особенно актуальным, в связи со вступлением нашей страны во Всемирную торговую организацию. Ассоциацией нарабатывается опыт участия в работе по обеспечению принципа «национального режима», то есть действия для иностранных лиц тех же правил, что и для российских предпринимателей. Иностранными компаниями, являющимися партнерами членов Ассоциации, высоко оценивается её роль в решении проблем в сфере защиты интеллектуальной собственности.

Одним из основных направлений деятельности Ассоциации является мониторинг отечественного рынка строительной и отделочной керамики, проведение исследований отдельных его аспектов. Для доведения наработанной информации до заинтересованной аудитории, которая достаточно обширна в силу специфики и востребованности поставляемых товаров, в перспективе планируется издание специального журнала. В настоящее время идет процесс обобщения информационного массива и поиска новых источников сведений, которые могли бы быть полезны не только дистрибьюторам и импортёрам строительной и отделочной керамики, но и строительным компаниям.

Пример создания и функционирования Ассоциации импортёров и дистрибьюторов строительной и отделочной керамики демонстрирует процесс осознания предпринимательским классом своего места и роли в современном российском гражданском обществе, поиска цивилизованных форм защиты своих интересов.

Такая Ассоциация, функционирующая в качестве «фабрики мысли», не является исключением, аналогичные объединения, имеющие различную направленность, существуют в Москве, Санкт-Петербурге, Нижнем Новгороде и т.д., что в свою очередь, указывает на то, что мы имеем дело не с частным случаем, а социальным явлением. На наш взгляд, имеются достаточные основания оценить деятельность фабрик мысли в России как перспективное направление развития гражданского общества в России. В этом контексте будет уместным привести оценку подобных явлений наблюдаемых в нашем обществе, высказанную Д.А. Медведевым на II Всероссийском гражданском форуме, организатором которого выступила Общественная палата РФ: «Наше гражданское общество рождалось в противоречивых событиях последних двух десятилетий. Но то, что оно сегодня является элементом политической жизни - это неоспоримый факт. Больше того, структурированное гражданское общество, сейчас проходит процесс его оформления, уже имеется, и в дальнейшем оно должно стать итогом нашего стабильного цивилизованного развития» ${ }^{8}$.

\section{Библиография:}

1. Малый и средний бизнес России: численность и отраслевое распределение. // Российское предпринимательство. № 4. 2011. - С. 46-51.

2. Манойло А.В. Роль культурно-цивилизационных моделей и технологий информационно-психологического воздействия в разрешении международных конфликтов. Текст диссертации на соиск. уч. ст. доктора политических наук. - М., 2009. - С. 9.

3. Волков Д.А. Перспективы гражданского общества в России. Доклад Аналитического Центра Юрия Левады (Левада-Центр). - М., 2011. - С. 50.

4. Сунгуров А.Ю. Институты-медиаторы и их развитие в современной России. Фабрики мысли и центры публичной политики. // Полис.2012. № 4.- С. 105.

5. Сунгуров А.Ю. Институты-медиаторы и их развитие в современной России. Современные палаты и консультативные советы федеральный и региональный опыт. // Полис. 2012. № 1. - С. 169.

6. Устав Ассоциации дистрибьюторов и импортеров строительной и отделочной керамики.[электронный pecypc] // Официальный сайт Ассоциации. URL: http:// www.askeramika.ru/index.php?page=docustav. (дата обращения 20.05.2013).

7. Выступление Д.А. Медведева на II Всероссийском гражданском форуме.[электронный ресурс] // Официальный сайт Общественной палаты РФ. URL: http://www.oprf.ru/newsblock/news/1567/chamber_news. (дата обращения 30.05.2013).

\section{References (transliteration):}

1. Manoylo A.V. Rol' kul'turno-civilizacionnyh modeley i tehnologiy informacionno-psihologicheskogo vozdeyst-

\footnotetext{
${ }^{8}$ Выступление Д.А. Медведева на IIВсероссийском гражданском форуме.[электронный ресурс] // Официальный сайт Общественной палаты РФ. URL: http://www.oprf.ru/newsblock/news/1567/ chamber_news. (дата обращения 30.05.2013).
} 
DOI: $10.7256 / 1811-9018.2013 .8 .9015$

При цитировании этой статьи сноска на dоі обязательна

\section{Право и политика $8(164) \cdot 2013$}

viya $\mathrm{v}$ razreshenii mezhdunarodnyh konfliktov. Tekst dissertacii na soisk. uch. st. doktora politicheskih nauk. - M., 2009. - S. 9.

2. Volkov D.A. Perspektivy grazhdanskogo obschestva v Rossii. Doklad Analiticheskogo Centra Yuriya Levady (Levada-Centr). - M., 2011. - C. 50.

3. Sungurov A.Yu. Instituty-mediatory $\mathrm{i}$ ih razvitie v sovremennoy Rossii. Fabriki mysli i centry publichnoy politiki. // Polis.2012. № 4.- S. 105.
4. Sungurov A.Yu. Instituty-mediatory i ih razvitie v sovremennoy Rossii. Sovremennye palaty i konsul'tativnye sovety federal'nyy i regional'nyy opyt. // Polis. 2012. № 1. - S. 169 .

5. Vystuplenie D.A. Medvedeva na II Vserossiyskom grazhdanskom forume.[elektronnyy resurs] // Oficial'nyy sayt Obschestvennoy palaty RF. URL: http://www.oprf.ru/ newsblock/news/1567/chamber_news. (data obrascheniya 30.05.2013). 